\title{
Experimental Study on Thermal Efficiency of Flat Plate Solar Collector Using $\mathrm{TiO}_{2} /$ Water Nanofluid
}

\author{
Hossein Chaji ${ }^{1,2}$, Yahya Ajabshirchi ${ }^{1}$, Esmaeil Esmaeilzadeh ${ }^{3}$, Saeid Zeinali Heris ${ }^{4}$, Mahdi Hedayatizadeh ${ }^{5}$ \& \\ Mostafa Kahani ${ }^{4}$ \\ ${ }^{1}$ Department of Agricultural Machinery Engineering, Faculty of Agriculture, University of Tabriz, Tabriz, Iran \\ ${ }^{2}$ Khorasan Razavi Agricultural and Natural Resources Research Center, Mashhad, Iran \\ ${ }^{3}$ Mechanical Engineering Department, University of Tabriz, Tabriz, Iran \\ ${ }^{4}$ Chemical Engineering Department, Engineering Faculty, Ferdowsi University of Mashhad, Mashhad, Iran \\ ${ }^{5}$ Faculty of Agriculture, University of Birjand, Birjand, Iran \\ Correspondence: Hossein Chaji, Department of Agricultural Machinery Engineering, Faculty of Agriculture, \\ University of Tabriz, Tabriz, Iran. E-mail: hchaji53@gmail.com
}

\author{
Received: July 14, 2013 Accepted: September 11, $2013 \quad$ Online Published: September 24, 2013 \\ doi:10.5539/mas.v7n10p60 URL: http://dx.doi.org/10.5539/mas.v7n10p60
}

\begin{abstract}
In this study, a small flat plate solar collector (FPSC) was fabricated and tested for studying the effects of different nano particle concentrations of $\mathrm{TiO}_{2}$ in water as base fluid. Three flow rates (i.e. 36, 72 and 108 $\mathrm{lit} / \mathrm{m}^{2} . \mathrm{hr}$ ) and four particles concentration ratios (i.e. $0,0.1,0.2$ and $0.3 \% \mathrm{wt}$ ) were investigated. Experimental testing method was selected based on EUROPEAN STANDARD EN 12975-2 as a quasi-dynamic test method (QDT). Adding nano particles to water brought about an improvement of initial efficiency of FPSC between 3.5 and $10.5 \%$ and the index of collector total efficiency between 2.6 and $7 \%$ relative to base fluid. Also the results indicate that the initial efficiency $\left(\eta_{0}\right)$ for 36,72 and $108 \mathrm{lit} / \mathrm{m}^{2} . \mathrm{hr}$ flow rates of water as base fluid were 0.4712 , 0.4998 and 0.5457 , respectively which reveals the increase of 6.1 and $15.8 \%$ of it in the two latter cases in comparison with the first case, $36 \mathrm{lit} / \mathrm{m}^{2}$.hr flow rate. In addition, the index of collector total efficiency of 72 and $108 \mathrm{lit} / \mathrm{m}^{2} . \mathrm{hr}$ mass flow rates has increased by 6.7 and $15.7 \%$, respectively in comparison with $36 \mathrm{lit} / \mathrm{m}^{2} . \mathrm{hr}$ mass flow rate.
\end{abstract}

Keywords: flat plate solar collector, thermal efficiency, nanofluid

\section{Introduction}

The most important benefit of renewable energy systems is the decrease of environmental pollution. The crisis of the energy cost and its demand increases exponentially with fossil energy nearing exhaustion for present and future time as well as the environmental and air pollution are being more severe, so the strong demand to use or produce a new or renewable, clean and low cost energy is raised to confront this crisis (Ali, 2013). Renewable energy sources such as sun energy can be substituted for exceeding human energy needs (Taki, Ajabshirch, Behfar, \& Taki, 2011). Solar energy as one of the most significant forms of renewable energy sources has drawn a lot of attention as there is a belief it can play a very important role in meeting a major part of our futures' need to energy (Hedayatizadeh et al., 2013). However solar energy as an eternal and widespread energy source has low density and is frequently changing as well as the gap between the time of radiation and consumption is the main disadvantage. Hence, collecting and storage of solar energy during radiation time is required for the consuming period.

Water is a good material for receiving and storage of solar energy and the solar water heater (SWH) is one of the fastest growing technologies in the renewable energies sector (Kumar \& Rosen, 2011). Water heating by solar energy is the most important application of direct solar energy use in the world today (Wongsuwan \& Kumar, 2005), while Flat Plate Solar Water Heater (FPSWH) is a well-known technology. The thermal efficiency of the solar water heaters has improved by using some techniques (Rezania, Taherian, \& Ganji, 2012). 
Up to now, many studies have been done in order to improve the thermal efficiency of SWHs (Koffi, Andoh, Gbaha, Toure, \& Ado, 2008; Jaisankar, Radhakrishnan, \& Sheeba, 2009a; Jaisankar, Radhakrishnan, \& Sheeba, 2009b; Alshamaileh, 2010; Kumar \& Rosen, 2010).

The many ways of increasing heat transfer through heat exchangers can be divided into two categories: Passive and active methods. Contrasts to active techniques, passive methods do not need an external force. Using nanofluids as heat transfer medium is a passive method for increasing heat transfer. In spite of many scientific works studying the effect of nanofluids application on thermal efficiency of heat exchangers, there exists very limited information about the study of nanofluids effect on flat-plate solar collectors.

Das, Choi, Yu, and Pradeep (2007) expressed that the nanofluids could be utilized to enhance heat transfer from solar collectors to storage tanks and to increase the energy density. Natarajan and Sathish (2009) also believed the novel approach of increasing the efficiency of solar water heater through the introduction of nanofluids instead of conventional heat transfer fluids.

Tiwari, Pradyumna, Ghosh and Sarkar (2013) investigated the effect of using $\mathrm{Al}_{2} \mathrm{O}_{3}$ nanofluid as an absorbing medium in a flat-plate solar collector theoretically. They also studied the effect of mass flow rate and particle volume fraction on the efficiency of the collector. Their results showed that using the optimum particle volume fraction $1.5 \%$ of $\mathrm{Al}_{2} \mathrm{O}_{3}$ nanofluid increases the thermal efficiency of solar collector in comparison with water as working fluid by $31.64 \%$.

Otanicar and Golden (2009) reported the experimental results on solar collector based on nanofluids composed of a variety of nano particles (carbon nano tubes, graphite, and silver). The efficiency improvements were up to $5 \%$ in solar thermal collectors by utilizing nanofluids as the absorption mechanism. The experimental and numerical results demonstrated an initial rapid increase in efficiency with volume fraction, followed by a leveling off in efficiency as volume fraction continues to increase.

Yousefi, Veysy, Shojaeizadeh and Zinadini (2012a, 2012b) studied the effect of $\mathrm{Al}_{2} \mathrm{O}_{3}$ and MWCNT water nanofluid on the efficiency of a FPSC (flat plate solar collector) experimentally. The results showed that using $\mathrm{Al}_{2} \mathrm{O}_{3}$ and MWCNT water nanofluids in comparison with water as working fluid increased the efficiency up to $28.3 \%$ and $35 \%$, respectively.

Taylor et al. (2011) investigated on applicability of nanofluids in high flux solar collectors. Experiments on a laboratory-scale nanofluid dish receiver suggest that up to $10 \%$ increase in efficiency is possible-relative to a conventional fluid- if operating conditions are chosen carefully for $0.125 \%$ volume fraction of graphite.

Anyway, up to now just a few studies have been done on nanofluids application in SWH, especially FPSC. Since FPSCs are the most commonly used systems in the renewable energies sector, any attempt for improving the rate of energy harvest seems very effective. Considering the previous studies, nanofluid is a new candidate for this aim. Therefore the objective of this experimental research is to study the effect of titanium di oxide $\left(\mathrm{TiO}_{2}\right)$ water nanofluid on a small scale FPSC as a heat transfer medium in comparison with water.

\begin{tabular}{|c|c|c|c|}
\hline \multicolumn{2}{|c|}{ Nomenclature } & \multirow{2}{*}{\multicolumn{2}{|c|}{$\begin{array}{ll}\mathrm{h}_{\mathrm{fi}} & \text { Heat transfer coefficient inside the tube } \\
\mathrm{m} & \text { Mass flow rate of fluid flow (Lit/s) } \\
\mathrm{Q}_{\mathrm{u}} & \text { Rate of useful energy gained }(\mathrm{W})\end{array}$}} \\
\hline$A_{c}$ & Surface area of solar collector $\left(\mathrm{m}^{2}\right)$ & & \\
\hline $\mathrm{C}_{\mathrm{b}}$ & Bond conductance & $\mathrm{R}^{2}$ & Coefficient of determination \\
\hline $\mathrm{C}_{\mathrm{p}}$ & Specific heat at constant pressure $(\mathrm{J} / \mathrm{kg} \mathrm{K})$ & $\mathrm{T}_{\mathrm{a}}$ & Ambient temperature $(\mathrm{C})$ \\
\hline $\mathrm{C}_{\mathrm{p}, \mathrm{bf}}$ & Heat capacity of base fluid (water) $(\mathrm{J} / \mathrm{kg} \mathrm{K})$ & $\mathrm{T}_{\mathrm{i}}$ & Inlet fluid temperature of solar collector $(\mathrm{C})$ \\
\hline$C_{p, n p}$ & Heat capacity of nanoparticles $(\mathrm{TiO} 2)(\mathrm{J} / \mathrm{kg} \mathrm{K})$ & $\mathrm{T}_{\mathrm{o}}$ & Outlet fluid temperature of solar collector (C) \\
\hline$C_{p, n f}$ & Heat capacity of nanofluid ( $\mathrm{J} / \mathrm{kg} \mathrm{K})$ & $\mathrm{U}_{\mathrm{l}}$ & Overall loss coefficient of solar collector $(\mathrm{W} / \mathrm{m} 2 \mathrm{~K})$ \\
\hline $\mathrm{D}$ & Tube outside diameter & \multicolumn{2}{|c|}{ Greek symbols } \\
\hline $\mathrm{D}_{\mathrm{i}}$ & Tube inside diameter & $\alpha$ & Absorptance of plate \\
\hline $\mathrm{F}$ & Fin efficiency & $\tau$ & Transmittance of glass cover \\
\hline $\mathrm{F}^{\prime}$ & Collector efficiency factor & $\eta_{0}$ & Initial efficiency \\
\hline $\mathrm{F}_{\mathrm{R}}$ & Heat removal factor & $\eta_{\mathrm{i}}$ & Instantaneous efficiency \\
\hline$G_{t}$ & Global solar radiation $(\mathrm{W} / \mathrm{m} 2)$ & $\varphi$ & Weight fraction of nanoparticles in nanofluid \\
\hline
\end{tabular}




\section{Materials and Methods}

\subsection{Nanofluid}

Two stages method was applied by dispersing of Titana powders $\left(\mathrm{TiO}_{2}\right.$ (rutile) nanoparticles with mean size of $20 \mathrm{~nm}$ and surface area of $40 \mathrm{~m}^{2} / \mathrm{gr}$ ) of $0.1,0.2$ and $0.3 \mathrm{wt} \%$ in double distilled water as base fluid.

As surface to volume ratio of material in nano scale is very large, surface tension between nano particles results in aggregation and deposits. Hence, surfactants have been introduced in order to solve this problem. In this research, several surfactants such as Triton X-100, Cetyl Tri methyl Ammonium Bromide (CTAB), Twin 20 and 80 were examined. It was found that using Triton X-100 and CTAB increases the stability time of nanofluid while through creation of air bulbs (foam) in nanofluid, the solar collector efficiency decreases. Hence, it was preferred to prepare the nanofluid without using surfactant.

Initially, the powder was added to double distilled water and agitated by magnetic stirrer for 6 hours. Afterwards, the mixture was treated by UP $400 \mathrm{~s}$ Ultrasonic Processor- manufactured by Hielscher Ultrasound Technologyfor 30 minutes (Figure 1). The prepared nanofluids could stay stable for 4 hours at least.

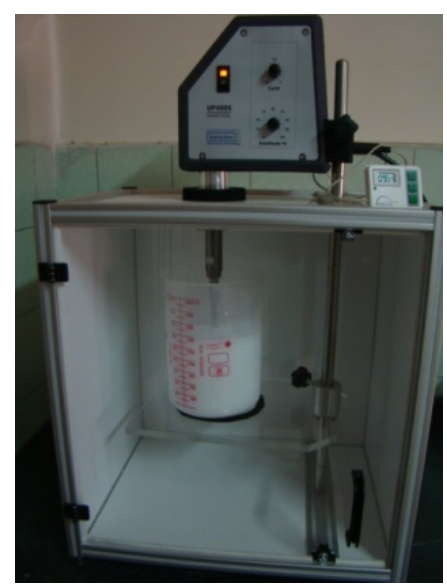

Figure 1. The nanofluid in UP 400s ultrasonic processor

\subsection{The Set up for Experiments}

In Figure 2 the schematic view of set up is shown. Three temperature measurements are required for solar collector testing i.e. ambient air temperature and the fluid temperature at the collector inlet and outlet. 1 in Figure 2 is the surrounding air temperature sensor. 2 is the flat plate solar collector (FPSC) while its details are summarized in Table 1. It is a glazed (one cover) solar collector that is exposed to south with tilt angle $55^{\circ} .3$ and 4 are inlet and outlet of heat transfer fluid to the FPSC, respectively. Two mercury bar thermometers at the inlet and outlet of solar collector measured the temperature of heat transfer fluid in 3 and 4, respectively with accuracy of $0.1{ }^{\circ} \mathrm{C}$. The bulbs of thermometers were placed inside the tubes completely. Simultaneously, temperatures of the three mentioned points were also measured by PT100 sensors for gaining higher accuracy. Pump 8 carried water through the collector, control valve 6 and finally container 7. Mass flow rate was measured directly by volumetric flow rate method in this location. To fulfill the quasi- steady state conditions, it was tried to have a slow change in inlet fluid temperature, hence a heat exchanger was applied (5 in Figure 2). Solar radiation $\left(\mathrm{G}_{\mathrm{t}}\right)$ was measured by a TES 1333 Solar Power Meter 9 with accuracy typically within $\pm 10 \mathrm{w} / \mathrm{m}^{2}$ and resolution $0.1 \mathrm{w} / \mathrm{m}^{2}$. The Prova AVM-03 anemometer also provided the accurate measurements of wind velocity with $\pm 3.0 \% \pm 0.1$ accuracy. 


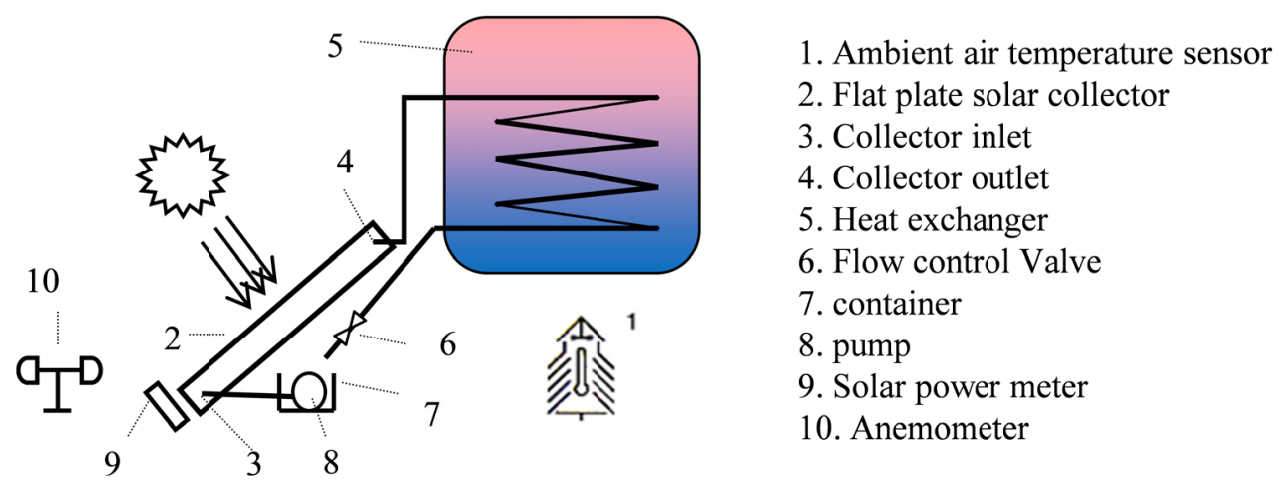

Figure 2. The experimental set up schematic

A small flat plate solar collector specified in Table 1 and Figure 2 was fabricated for experiments that illustrated in Figure 3.

Table 1. The specifications of the FPSC

\begin{tabular}{lll}
\hline specification & Dimension & material \\
\hline Absorber plate length & $0.5 \mathrm{~m}$ & Copper \\
Absorber plate width & $0.2 \mathrm{~m}$ & \\
Absorber plate thickness & $0.001 \mathrm{~m}$ & \\
Inner diameter of Riser Tube & $0.003 \mathrm{~m}$ & Copper \\
Outside diameter of Riser Tube & $0.004 \mathrm{~m}$ & \\
Cover thickness & $0.005 \mathrm{~m}$ & Glass \\
Edges thickness & $0.016 \mathrm{~m}$ & MDF \\
Back thickness & $0.05 \mathrm{~m}$ & Rockwool \\
The tilt angle & $55^{\circ}$ & \\
The tube welded to plate all over & & \\
Absorber plate painted by black matte & & \\
\hline
\end{tabular}

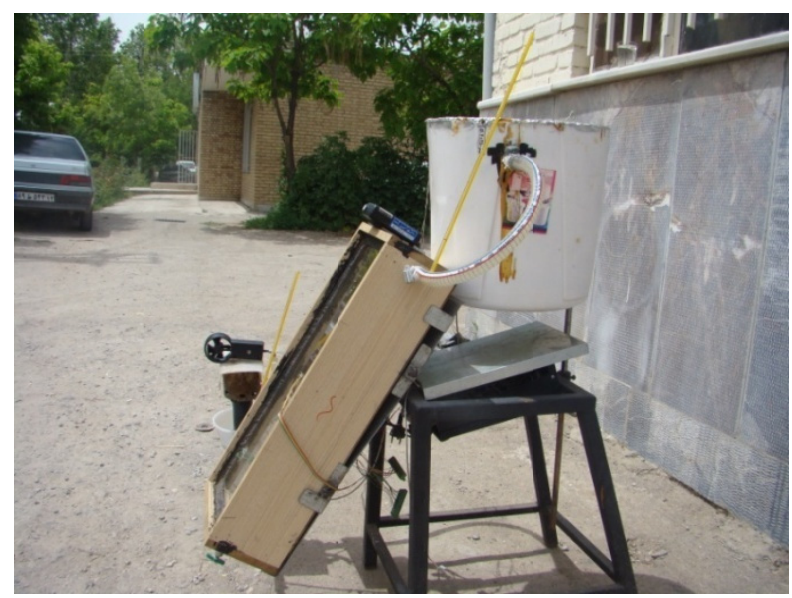

Figure 3. The experimental flat plate solar collector 


\subsection{The Procedure}

Experimental testing method was according to EUROPEAN STANDARD EN 12975-2 (2006) as a quasi-dynamic test method (QDT). To facilitate the understanding of this approach, the recommended test sequence and other test requirements given here are closely connected to those widely accepted for steady-state testing of solar thermal collectors. The setup is shown in Figure 3 investigated in Mashhad, Iran (Latitude $36^{\circ} \mathrm{N}$ and longitude $60^{\circ} \mathrm{E}$ ). According to EUROPEAN STANDARD EN 12975-2 the collector shall be tested over its operating temperature range under clear sky conditions in order to determine its performance characteristic. In a later revision of this method, three different inlet temperatures were applied.

The first inlet temperature was selected around ambient air temperature to obtain an accurate determination of $\eta_{0}$. The second inlet temperature was selected around $52{ }^{\circ} \mathrm{C}$ and finally the highest fluid inlet temperature was chosen around $74^{\circ} \mathrm{C}$.

Three flow rates i.e. D1 $=36, \mathrm{D} 2=72$ and $\mathrm{D} 3=108 \mathrm{lit} / \mathrm{m}^{2}$.hr and four particle concentration ratios i.e. $\varphi_{0}=0$ (for basefluid), $\varphi_{1}=0.1, \varphi_{2}=0.2$ and $\varphi_{3}=0.3 \%$ wt were investigated to gain 12 cases. As mentioned above, there were three inlet temperature for each case. For each inlet temperature, four data points were obtained that all of them were done around solar noon while $G_{t}$ was between 900 and $1000 \mathrm{~W} / \mathrm{m}^{2}$.

The change in inlet temperature was done after completion of each test sequence. After each change in collector inlet temperature or flow rate, a pre-conditioning period of at least 20 min was considered to ensure that the initial state of the collector faded away and did not influence the result of the parameter identification.

The useful energy gain $\left(Q_{u}\right)$ of the FPSC determined by:

$$
\mathrm{Q}_{\mathrm{u}}=\mathrm{m} \cdot \mathrm{C}_{\mathrm{p}}\left(\mathrm{T}_{\mathrm{o}}-\mathrm{T}_{\mathrm{i}}\right)
$$

Where $m$ and $C_{p}$ are mass flow rate and heat capacity of fluid, respectively.

Koffi et al. (2008) used Equation 2 in order to calculate heat capacity of water:

$$
\begin{gathered}
\mathrm{C}_{\mathrm{p}, \mathrm{w}}=4226-3.244 \mathrm{~T}_{\mathrm{fm}}+0.0575 \mathrm{~T}_{\mathrm{fm}}{ }^{2} \\
\mathrm{~T}_{\mathrm{fm}}=\left(\mathrm{T}_{\mathrm{o}}+\mathrm{T}_{\mathrm{i}}\right) / 2
\end{gathered}
$$

Where $\mathrm{T}_{\mathrm{fm}}$ is the mean temperature of working fluid inside the collector in ${ }^{\circ} \mathrm{C}$.

Heat capacity of nanofluid is also calculated by (Kayhani, 2012):

$$
\mathrm{C}_{\mathrm{p}, \mathrm{nf}}=\mathrm{C}_{\mathrm{p}, \mathrm{np}}(\varphi)+\mathrm{C}_{\mathrm{p}, \mathrm{w}}(1-\varphi)
$$

The useful energy gain was expressed by (Duffie \& Beckman, 1991):

$$
\mathrm{Q}_{\mathrm{u}}=\mathrm{A}_{\mathrm{c}} \mathrm{F}_{\mathrm{R}}\left(\mathrm{G}_{\mathrm{t}}(\tau \alpha)-\mathrm{U}_{1}\left(\mathrm{~T}_{\mathrm{i}}-\mathrm{T}_{\mathrm{a}}\right)\right)
$$

For each test, instantaneous efficiency $\left(\eta_{i}\right)$ was determined from ratio of useful energy gain $\left(Q_{u}\right)$ to incident radiation $\left(\mathrm{A}_{\mathrm{c}} \mathrm{G}_{\mathrm{t}}\right)$ :

$$
\eta_{i}=\frac{Q_{u}}{A_{c} G_{t}}=\frac{m \cdot C_{p}\left(T_{o}-T_{i}\right)}{A_{c} G_{t}}=F_{R}(\tau \alpha)-F_{R} U_{1}\left(\frac{T_{i}-T_{a}}{G_{t}}\right)
$$

If $U_{l}, F_{R}$ and $(\tau \alpha)$ were all constant, the plots of $\eta_{i}$ versus $\left(T_{i}-T_{a}\right) / G_{t}$ would be straight lines with intercept $F_{R}(\tau \alpha)$ and slope $-F_{R} U_{l}$. However, they are not and scattered data are expected. In spite of these difficulties, long-time performance estimate of many solar heating systems, collectors can be characterized by the intercept and slope (i.e., by $F_{R}(\tau \alpha)$ and $\left.-F_{R} U_{1}\right)$ (Duffie \& Beckman, 1991).

Using curve fitting tool box of Matlab, a line was fitted to experimental data of thermal efficiency versus the reduced temperature parameters, $\left(T_{i}-T_{a}\right) / G_{t}$, for each case.

Goodness of fitting was determined by $\mathrm{R}^{2}$, SSE (Sum of Square Error) and RMSE(Root- Mean- Square error):

$$
\operatorname{SSE}=\sum_{\mathrm{i}=1}^{\mathrm{n}}\left(\eta_{\text {exp }, \mathrm{i}}-\eta_{\text {pred, } \mathrm{i}}\right)^{2}
$$




$$
\text { RMSE }=\sqrt{\frac{\sum_{\mathrm{i}=1}^{\mathrm{n}}\left(\eta_{\text {exp } \mathrm{i}}-\eta_{\text {pred, } \mathrm{i}}\right)^{2}}{\mathrm{n}}}
$$

Where $\eta_{\text {exp,i }}$ and $\eta_{\text {pred,i }}$ are experimental and predicted efficiency of solar collector and $\mathrm{n}$ is data numbers for each model.

Finally the area under curves as index of collector total efficiency was used for comparing the cases.

\section{Results and Discussion}

\subsection{Water as Heat Transfer Medium}

First of all the collector was tested for water as working fluid. To gain such a goal, three flow rates D1, D2 and D3 were selected in such a way that D1 and D2 were in laminar flow range completely and D3 was in transient state from laminar to turbulent flow. The experimental results are shown in Figure 4 and Table 2. It can be seen for flow rates D1, D2 and D3 of water, the collector efficiencies at initial point, $T_{i}-T_{a}=0$ (i.e. $\eta_{0}$ ), are $0.4712,0.4998$ and 0.5457 , respectively. As the mass flow rate through the collector increases, the temperature rise through the collector decreases. This causes lower losses and there is a corresponding increment in the useful energy gain. This gain is reflected by an increase in the collector heat removal factor $F_{R}$ (Duffie \& Beckman, 1991). Intercepts of models equal $\left(\mathrm{F}_{\mathrm{R}}(\tau \alpha)\right)$ that in this term, multiple $(\tau \alpha)$ for a determined collector is constant, so increasing of $F_{R}$ results in enhancing of $\left(F_{R}(\tau \alpha)\right)$. Although increasing of mass flow rate through the collector increases $F_{R}$, because of reduction of temperature through the collector, $U_{1}$ experiences a bit decrease, however multiple $\left(\mathrm{F}_{\mathrm{R}} \mathrm{U}_{1}\right)$ increases in total and $\left(-\mathrm{F}_{\mathrm{R}} \mathrm{U}_{1}\right)$ reduces. Therefore the slopes for flow rates D1, D2 and D3 are $-8.304,-8.827$ and -9.582 , respectively. Since slopes of models are negative, one can see that increasing $\mathrm{T}_{\mathrm{i}}-\mathrm{T}_{\mathrm{a}}$, causes the efficiency to zero (in $\mathrm{x}_{\max }$ ).

Another parameter for comparing the collector efficiency is ' $A$ ' (Area under the curve $\times 100$ ) that has been brought in Table 2. It represents the entire range of the collector efficiency (from $\mathrm{x}=0$ to $\mathrm{x}_{\max }$ ). Amounts of ' $A$ ' for $\mathrm{D} 1 \varphi_{0}, \mathrm{D} 2 \varphi_{0}$ and $\mathrm{D} 3 \varphi_{0}$ are $1.34,1.43$ and 1.55 , respectively which proves the $6.7 \%$ and $15.7 \%$ increase of $\mathrm{D} 2 \varphi_{0}$ and $\mathrm{D} 3 \varphi_{0}$ relevant to $\mathrm{D} 1 \varphi_{0}$. Intercept, slope and ' $A$ ' for $\mathrm{D} 3 \varphi_{0}$ comparing to $\mathrm{D} 2 \varphi_{0}$ have changed more as the flow type of D3 has changed from laminar to turbulent.

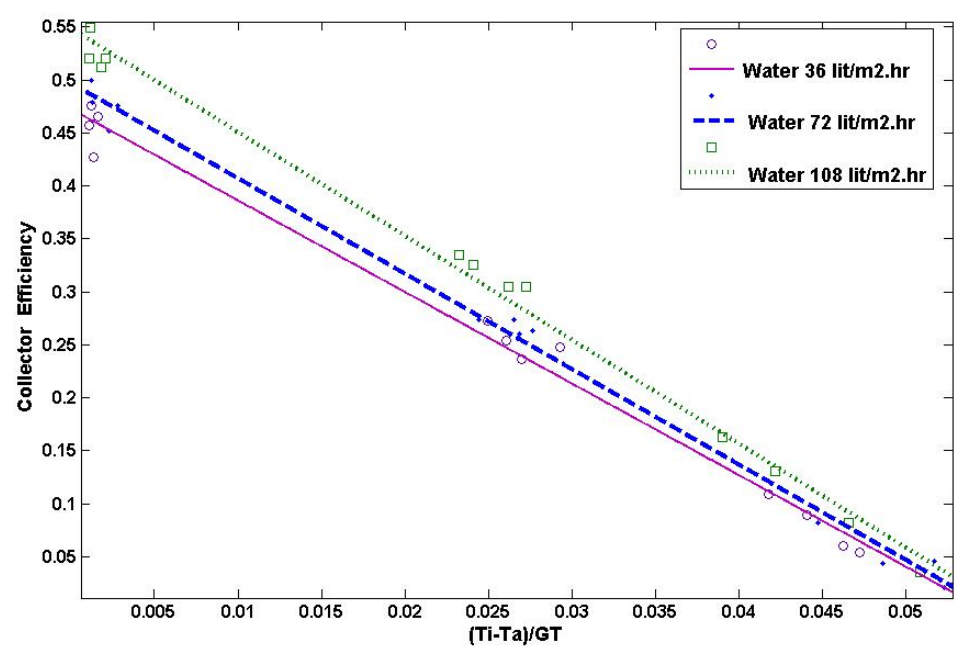

Figure 4. Collector efficiency for three flow rates of water as working fluid in 
Table 2. The experimental results

\begin{tabular}{cccccc}
\hline & Model & $\begin{array}{c}\text { Area under the } \\
\text { curve } \times 100(A)\end{array}$ & $\mathrm{R}^{2}$ & SSE & RMSE \\
\hline $\mathrm{D} 1 \varphi_{0}$ & $\eta=-8.304 \mathrm{x}+0.4712$ & 1.34 & 0.9738 & 0.008 & 0.025 \\
$\mathrm{D} 2 \varphi_{0}$ & $\eta=-8.827 \mathrm{x}+0.4998$ & 1.43 & 0.988 & 0.004 & 0.0191 \\
$\mathrm{D} 3 \varphi_{0}$ & $\eta=-9.582 \mathrm{x}+0.5457$ & 1.55 & 0.989 & 0.0035 & 0.0188 \\
$\mathrm{D} 1 \varphi_{1}$ & $\eta=-9.145 \mathrm{x}+0.5089$ & 1.4 & 0.982 & 0.006 & 0.024 \\
$\mathrm{D} 1 \varphi_{2}$ & $\eta=-9.27 \mathrm{x}+0.5123$ & 1.41 & 0.988 & 0.004 & 0.02 \\
$\mathrm{D} 1 \varphi_{3}$ & $\eta=-9.396 \mathrm{x}+0.5161$ & 1.42 & 0.98 & 0.0065 & 0.025 \\
$\mathrm{D} 2 \varphi_{1}$ & $\eta=-9.784 \mathrm{x}+0.5418$ & 1.49 & 0.9846 & 0.005 & 0.023 \\
$\mathrm{D} 2 \varphi_{2}$ & $\eta=-9.88 \mathrm{x}+0.5455$ & 1.52 & 0.9897 & 0.0044 & 0.021 \\
$\mathrm{D} 2 \varphi_{3}$ & $\eta=-10.03 \mathrm{x}+0.5524$ & 1.53 & 0.987 & 0.0045 & 0.02 \\
$\mathrm{D} 3 \varphi_{1}$ & $\eta=-10.03 \mathrm{x}+0.5649$ & 1.59 & 0.9865 & 0.0053 & 0.023 \\
$\mathrm{D} 3 \varphi_{2}$ & $\eta=-10.28 \mathrm{x}+0.5717$ & 1.59 & 0.9831 & 0.006 & 0.026 \\
$\mathrm{D} 3 \varphi_{3}$ & $\eta=-10.22 \mathrm{x}+0.5731$ & 1.60 & 0.9907 & 0.0038 & 0.0194 \\
\hline
\end{tabular}

\subsection{Nanofluid as a Heat Transfer Medium}

So far, many researches have proven that the nanofluids enhance the heat transfer coefficient as comparing with conventional fluid. In this research, to evaluate the effect of nanofluid on solar collector efficiency, three levels of $\mathrm{TiO}_{2}$ nano particles concentrations (without using surfactants) were examined and the results were compared with those of water.

Figure 5 represents the results for three levels of nano particle concentrations comparing with base fluid for mass flow rate $36 \mathrm{lit} / \mathrm{m}^{2} \mathrm{hr}$. The results show that the intercepts $\left(\eta_{0}\right)$ for $\mathrm{D} 1 \varphi_{0}, \mathrm{D} 1 \varphi_{1}, \mathrm{D} 1 \varphi_{2}$ and $\mathrm{D} 1 \varphi_{3}$ were 0.4712 , $0.5089,0.5123$ and 0.5161 , respectively while for three levels of nanofluid have been nearly in the same level and more than $\mathrm{D} 1 \varphi_{0}$ with $4 \%$. Diffusion and relative movement of nanoparticles near tube wall lead to rapid heat transfer from wall to nanofluid (Kahani, Heris, \& Mousavi, 2013). The slopes became steeper for nanofluids comparing to water which shows the effect of using nanofluids in enhancement of the collector heat removal factor $\left(\mathrm{F}_{\mathrm{R}}\right)$. Also 'A' for $\mathrm{D} 1 \varphi_{1}, \mathrm{D} 1 \varphi_{2}$ and $\mathrm{D} 1 \varphi_{3}$ in comparison with $\mathrm{D} 1 \varphi_{0}$ has increased by $4.6,5.2$ and $6 \%$, respectively. One can conclude that augmentation of particle concentrations above $0.1 \%$ wt has not been such effective.

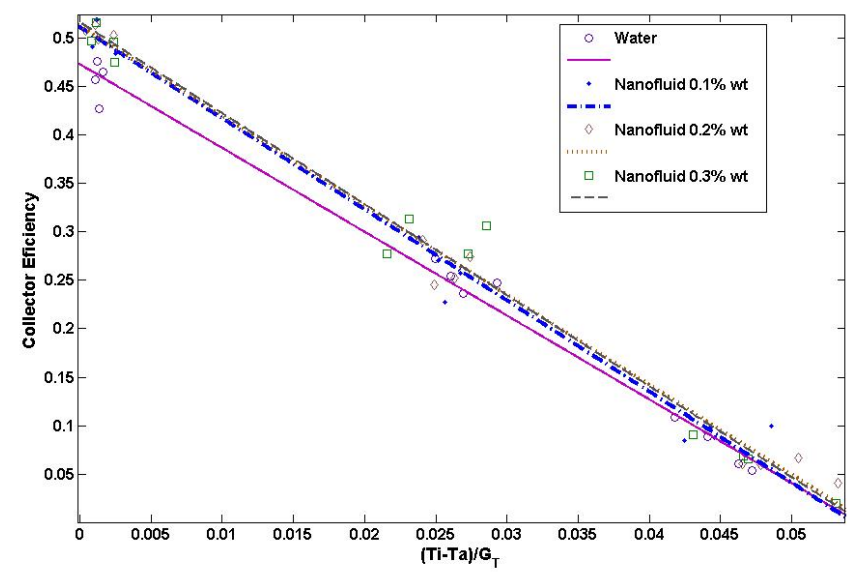

Figure 5. Collector efficiency for mass flow rate $36 \mathrm{lit} / \mathrm{m}^{2} \mathrm{hr}$

Figure 6 represents the models fitted on experimental data for $\mathrm{D} 2 \varphi_{0}, \mathrm{D} 2 \varphi_{1}, \mathrm{D} 2 \varphi_{2}$ and $\mathrm{D} 2 \varphi_{3}$. The initial efficiencies $\left(\eta_{0}\right)$ are $0.4998,0.5418,0.5455$ and 0.5524 , respectively which shows in case of equality between 
the inlet and ambient temperatures, nanofluids increases collector efficiency by 4 to $5 \%$ in comparison to the base fluid for this mass flow rate. The areas under the curves for $\mathrm{D} 2 \varphi_{1}, \mathrm{D} 2 \varphi_{2}$ and $\mathrm{D} 2 \varphi_{3}$ are also $1.49,1.52$ and 1.53 being more than $\mathrm{D} 2 \varphi_{0}$ by $4.2,6.3$ and $7 \%$, respectively.

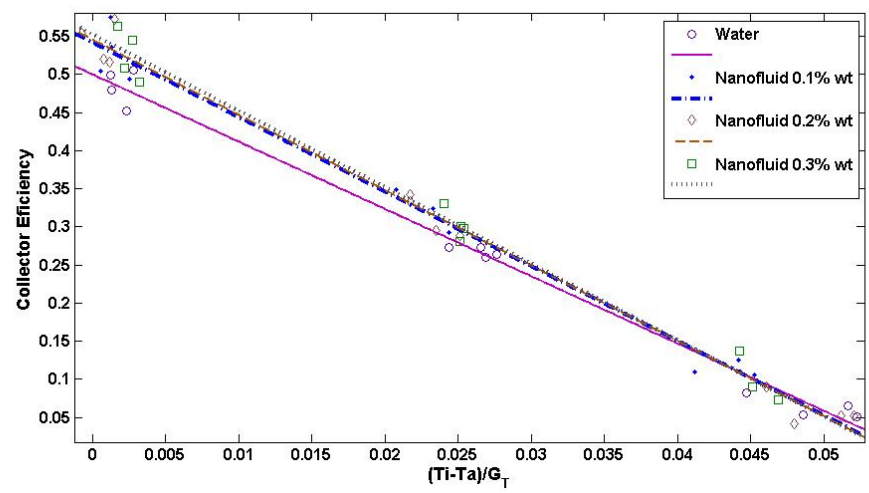

Figure 6. Collector efficiency for mass flow rate $72 \mathrm{lit} / \mathrm{m}^{2} \mathrm{hr}$

Finally, Figure 7 illustrates the results of mass flow rate $108 \mathrm{lit} / \mathrm{m}^{2} \mathrm{hr}$ on collector efficiency while considering water and nanofluids as the working fluids. Intercepts and slopes for $\mathrm{D} 3 \varphi_{0}, \mathrm{D} 3 \varphi_{1}, \mathrm{D} 3 \varphi_{2}$ and $\mathrm{D} 3 \varphi_{3}$ are 0.5457 , $0.5649,0.5717,0.5731$ and $-9.582,-10.03,-10.28,-10.22$, respectively. The same as the previous cases, intercepts $\left(\mathrm{F}_{\mathrm{R}}(\tau \alpha)\right)$ and slopes $\left(\mathrm{F}_{\mathrm{R}} \mathrm{U}_{1}\right)$ relevant to nanofluids are more than those of base fluid but not much significant. Kahani et al. (2013) expressed that for low Reynolds number the heat transfer coefficient is mainly proportional to the fluid thermal conductivity. The other main effects of the nanopowders inside the fluid 'considering the Brownian motion and fluctuation of the nanoparticles' change the flow structure of the fluid to a semi turbulent regime with a flattened transverse temperature gradient in the bulk of the fluid, which leads to enhance the nanofluid convective heat transfer. But at a higher Reynolds this mechanism is not dominant. In other words, at higher flow rate, the heat transfer coefficient has no considerable dependency to the thermal conductivity of the fluid. Therefore, the effect of thermal conductivity becomes less pronounced. Since, in the presence of nanopowders, the aforementioned heat transfer enhancement ratio decreases for a higher Reynolds number.

The areas under the curves for $\mathrm{D} 3 \varphi_{1}, \mathrm{D} 3 \varphi_{2}$ and $\mathrm{D} 3 \varphi_{3}$ are 2.6, 2.6 and $3.2 \%$ more than that of $\mathrm{D} 3 \varphi_{0}$. The results also show the effect of nanofluids on solar collector efficiency is less for mass flow rate of D3 comparing with D2 and D1. Increasing mass flow rate or using nanofluids instead of base fluid are methods for increasing collector efficiency factor $\left(\mathrm{F}^{\prime}\right)$ through increasing of heat transfer coefficient inside the tube $\left(\mathrm{h}_{\mathrm{fi}}\right)$ (Duffi \& Beckman, 1991).

$$
F^{\prime}=\frac{\frac{1}{U_{1}}}{W\left[\frac{1}{U_{1}[D+(W-D) F]}+\frac{1}{C_{b}}+\frac{1}{\pi D_{i} h_{\mathrm{f}_{i}}}\right]}
$$

Considering other collector characteristics invariant, increasing of $\mathrm{h}_{\mathrm{f}_{\mathrm{i}}}$ enhances $\mathrm{F}^{\prime}$ only up to a certain limit. In other words, for improving the effectiveness of $h_{f_{i}}$, it is nececery to select the other solar collector characteristics correctly when applying nanofluids. 


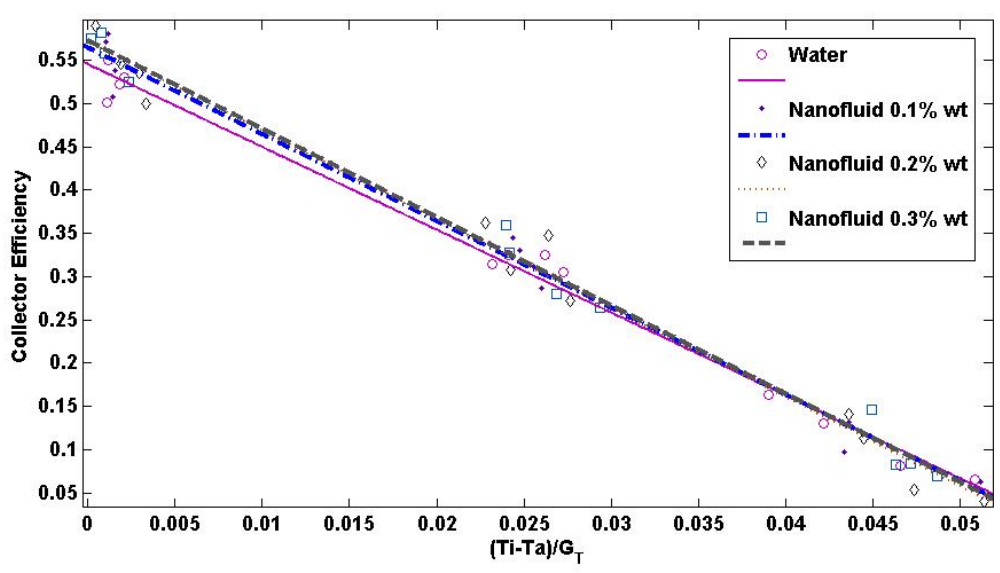

Figure 7. Collector efficiency for mass flow rate $108 \mathrm{lit} / \mathrm{m}^{2} \mathrm{hr}$

\section{Conclusion}

The effect of different nano particle concentrations of $\mathrm{TiO}_{2}$ mixed with water as base fluid was examined on solar collector efficiency for different mass flow rates. A line fitted on experimental data $\eta_{i}$ versus $\left(T_{i}-T_{a}\right) /$ $G_{t}$ for each case. The area under the curve as an index was used for comparing the effects of mass flow rates and nano particle concentrations on the collector total efficiency.

The results indicated the increase of mass flow rates of base fluid inside the solar collector enlarged the index of total collector efficiency area under the curves up to $15.7 \%$. Also, adding the nano particles to water improved the index of collector efficiency -area under the curve - between 2.6 and $7 \%$ relative to base fluid at the same flow rate.

In the highest mass flow rate $\left(108 \mathrm{lit} / \mathrm{m}^{2} \mathrm{hr}\right)$ the effect of nanofluid was not that in comparison with two other levels of flow rates ( 36 and $72 \mathrm{lit} / \mathrm{m}^{2} \mathrm{hr}$ ). It may be attributed to the fact that in the presence of nanopowders, the heat transfer enhancement ratio decreases for a higher Reynolds number and another reason is: while the other collector characteristics are invariant, increasing the heat transfer coefficient inside the tube can be effective on the collector efficiency only up to a certain limit and passing such a limit may not be much effective. Therefore the enhancement of collector efficiency requires the other design parameters to be carefully chosen while using nanofluid.

\section{Acknowledgements}

We want to appreciate Professor Mario Motta and his colleagues at the Department of Energy of the Polytechnic University of Milan for their helps. Also we would thank Nanotechnology Initiative Council of Iran and University of Tabriz for their financial supports of this research.

\section{References}

Ali, M. H. (2013). Analysis Study of Solar Tower Power Plant \& Its Configuration Effects on Its Performance in Iraq (Baghdad City). Modern Applied Science, 7(4), 55-69. http://dx.doi.org/10.5539/mas.v7n4p55

Alshamaileh, E. (2010). Testing of a new solar coating for solar water heating applications. Solar Energy, 84, 1637-1643. http://dx.doi.org/10.1016/j.solener.2010.06.003

Anonymous. (2006). EUROPEAN STANDARD EN 12975-2; Thermal solar systems and components - Solar collectors - Part 2: Test Methods. www.uni.com

Das, S. K., Choi, S. U. S., Yu, W., \& Pradeep, T. (2007). Nanofluid Science and Technology. John Wiley \& Sons, Inc., Publication.

Duffie, J. A., \& Beckman, W. A. (1991). Solar engineering of thermal processes. Wiley publication.

Hedayatizadeh, M., Ajabshirchi, Y., Sarhaddi, F., Safavinejad, A., Farahat, S., \& Chaji, H. (2013). Thermal and Electrical Assessment of an Integrated Solar Photovoltaic Thermal (PV/T) Water Collector Equipped with a Compound Parabolic Concentrator (CPC). International Journal of Green Energy, 10(5), 494-522. http://dx.doi.org/10.1080/15435075.2012.678524 
Jaisankar, S., Radhakrishnan, T. K., \& Sheeba, K. N. (2009a). Experimental studies on heat transfer and friction factor characteristics of thermosyphon solar water heater system fitted with spacer at the trailing edge of twisted tapes. Applied Thermal Engineering, 29, 1224-1231. http://dx.doi.org/10.1016/j.applthermaleng.2008.06.009

Jaisankar, S., Radhakrishnan, T. K., \& Sheeba, K. N. (2009b). Experimental studies on heat transfer and friction factor characteristics of forced circulation solar water heater system fitted with helical twisted tapes. Solar Energy, 83, 1943-1952. http://dx.doi.org/10.1016/j.solener.2009.07.006

Kahani, M., Zeinali Heris, S., \& Mousavi, S. M. (2013). Comparative study between metal oxide nanopowders on thermal characteristics of nanofluid flow through helical coils. Powder Thechnology, 246, 82-92. http://dx.doi.org/10.1016/j.powtec.2013.05.010

Koffi, P. M. E., Andoh, H. Y., Gbaha, P., Toure, S., \& Ado, G. (2008). Theoretical and experimental study of solar water heater with internal exchanger using thermo siphon system. Energy Conversion and Management, 49, 2279-2290. http://dx.doi.org/10.1016/j.enconman.2008.01.032

Kumar, R., \& Rosen, M. A. (2010). Thermal performance of Integrated collector-storage solar water heater with corrugated absorber surface. Applied Thermal Engineering, 30, 1764-1768. http://dx.doi.org/10.1016/j.applthermaleng.2010.04.007

Kumar, R., \& Rosen, M. A. (2011). Integrated collector-storage solar water heater with extended storage unit. Applied Thermal Engineering, 31, 348-354. http://dx.doi.org/10.1016/j.applthermaleng.2010.09.021

Natarajan, E., \& Sathish, R. (2009). Role of nanofluids in solar water heater. The International Journal of Advanced Manufacturing Technology. http://dx.doi.org/10.1007/s00170-008-1876-8

Otanicar, T., \& Golden, J. (2009). Comparative environmental and economic analysis of conventional and nanofluid solar hot water technologies. Environ. Sci. Technol., 43, $6082 \mathrm{e} 7$.

Rezania, A., Taherian, H., \& Ganji, D. D. (2012). Experimental Investigation of a Natural Circulation Solar Domestic Water Heater Performance Under Standard Consumption Rate. International Journal of Green Energy, 9(4), 322-334. http://dx.doi.org/10.1080/15435075.2011.652002

Taki, M., Ajabshirchi, Y., Behfar, H., \& Taki, M. (2011). Experimental Investigation and Construction of PV Solar Tracker Control System Using Image Processing. Modern Applied Science, 5(6), 237-244. http://dx.doi.org/10.5539/mas.v5n6p237

Taylor, R. A., Phelan, P. E., Otanicar, T. P., Walker, C. A., Nguyen, M., Trimble, S., \& Prasher, R. (2011). Applicability of Nanofluids in High Flux Solar Collectors. Renewable and Sustainable Energy, 3(2), 023104. http://dx.doi.org/10.1063/1.3571565

Tiwari, A., K. Pradyumna Ghosh, P., Sarkar, J. (2013). Solar Water Heating Using Nanofluids -A Comprehensive Overview And Enveronmental Impact Analysis. International Journal of Emerging Technology and Advanced Engineering, 3(Special Issue 3), 221-224. Retrieved from http://www.ijetae.com/files/Conference\%20ICERTSD-2013/IJETAE_ICERTSD_0213_35.pdf

Wongsuwan, W., \& Kumar, S. (2005). Forced circulation solar water heater performance prediction by TRNSYS and ANN. International Journal of Sustainable Energy, 24(2), 69-86. http://dx.doi.org/10.1080/14786450512331329565

Yousefi, T., Veysy, F., Shojaeizadeh, E., \& Zinadini, S. (2012a). An experimental investigation on the effect of $\mathrm{Al}_{2} \mathrm{O}_{3}-\mathrm{H}_{2} \mathrm{O}$ nanofluid on the efficiency of flat-plate solar collectors. Renewable Energy, 39, 293-298. http://dx.doi.org/10.1016/j.renene.2011.08.056

Yousefi, T., Veysy, F., Shojaeizadeh, E., \& Zinadini, S. (2012b). An experimental investigation on the effect of MWCNT $-\mathrm{H}_{2} \mathrm{O}$ nanofluid on the efficiency of flat-plate solar collectors. Experimental Thermal and Fluid Science, 39, 207-212. http://dx.doi.org/10.1016/j.expthermflusci.2012.01.025

\section{Copyrights}

Copyright for this article is retained by the author(s), with first publication rights granted to the journal.

This is an open-access article distributed under the terms and conditions of the Creative Commons Attribution license (http://creativecommons.org/licenses/by/3.0/). 